\title{
Commercial collaborations do not encourage misconduct
}

There are very little data to indicate that the professional conduct of researchers is affected when their funding comes from a corporation with a vested interest in the outcome of a particular set of experiments, says Sheldon Krimsky, head of the Environment and Society Program at Tufts University (Medford, MA). But he notes that "Graying the definition [of scientific misconduct] could potentially give more scope for misconduct" in collaborations of university researchers with business. The need to clearly delineate scientific misconduct from mere scientific bias arose in May when $\mathbf{5 0}$ professional societies, under the umbrella of the Federation of American Societies for Experimental Biology (FASEB, Bethesda, MD) objected to a redefinition of scientific misconduct in a report from the Commission on Research Integrity (CRI, Rockville, MD).

The CRI report "Integrity and Misconduct in Research," which got a mixed reception when it was published in January, had recommended replacing the original terms "fabrication, falsification, and plagiarism" with the more nebulous terms "misappropriation, interference, and misrepresentation." Ralph Bradshaw (University of California, Irvine), president of FASEB, says "The definition of scientific research conduct must be sufficiently precise to provide an unambiguous basis for investigating and adjudicating cases of alleged misconduct and serve as a clear guide for practicing scientists." For Bradshaw, the present CRI definition is "too broad and too vague." The scientific societies undersigned a joint letter to William Raub, secretary of the Department of Health and Human Services (Washington, DC), protesting the report's recommendations.

However, there is still concern that financial pressures on researchers will lead to increased incidence of misconduct, whatever its definition. Allan Shipp, a staff member of the Committee on Research Integrity at the Association of American Medical Colleges (Washington, DC), thinks that scientific bias arising from collaborative research with industry is unlikely to be a major problem.
"Researchers receiving funding from government sources are just as likely to bias their results to ensure grant renewals and publication as they are to tailor them to suit their industrial sponsors," he says.

A recent dispute between Boots Company (Nottingham, UK) and a research team headed by Betty Dong at the University of California, San Francisco (UCSF) reinforces Shipp's view. The UCSF group was hired by Boots to "demonstrate" that Synthroid, its lead product against hypothyroidism, was more efficacious than generic drugs from competitors, but they found no evidence to support such a claim. At the time, Boots was about to clinch a multimillion dollar deal selling its drug division to BASF (Ludwigshafen, Germany). "Despite pressure from Boots to suppress their findings, Dong's group still attempted to publish," says Shipp. "This is one case at least where the researcher resisted the temptation to compromise principles to suit the demands of the corporate backer."

Andrew Marshall

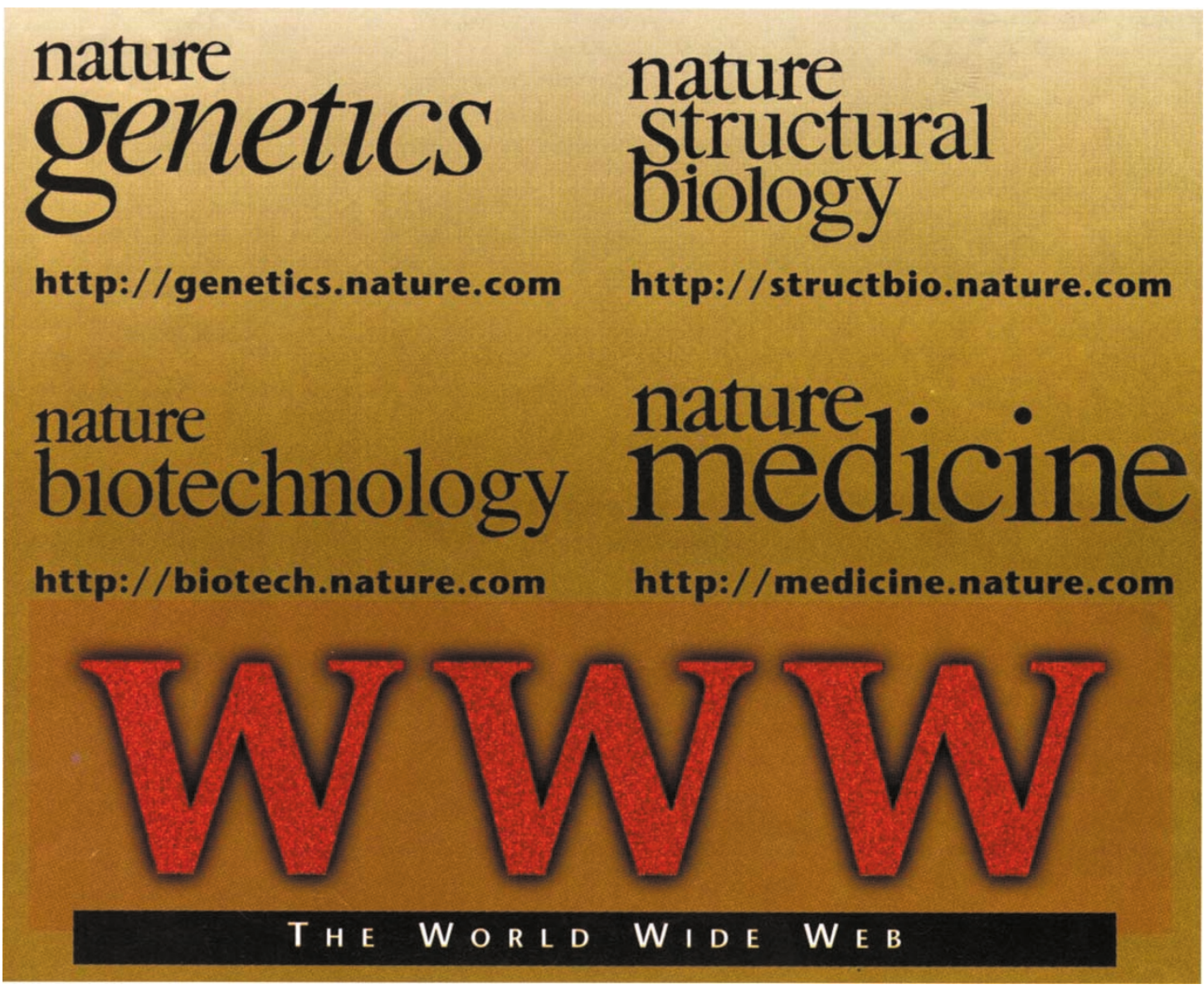

